\title{
Overuse: medical novelty or age-old phenomenon?
}

\section{Uso excessivo: novidade médica ou fenômeno antigo?}

\section{João Ricardo Pinto Lopes ${ }^{1}$ João Souza Filho Carlos Danilo Crusoé Gomes ${ }^{3}$ (1) Luís Cláudio Lemos Correia 4 (D)}

'Corresponding author. Escola Bahiana de Medicina e Saúde Pública (Salvador). Bahia, Brazil. jrpintolopes@yahoo.com.br ${ }^{2-4}$ Escola Bahiana de Medicina e Saúde Pública (Salvador). Bahia, Brazil. jsfilho41@gmail.com, crusoegomes@yahoo.com.br, luisclcorreia@gmail.com

ABSTRACT | INTRODUCTION: Mentions of overuse tend to imply it is a recent phenomenon as if irrationality was brought about by technological advances and the development of new procedures. However, it is possible that physicians have been prone to the same cognitive biases since antiquity, also performing inappropriate and excessive procedures. This raises the question of whether the contemporary issue of overuse is a modern phenomenon or inherited from a multi-millennial medical tradition. OBJECTIVE: To infer an answer to this question by summarizing the medical literature about overuse throughout the history of medicine. METHODS: Medical overuse is defined as futile, low-value procedures characterized by excessive use of methods with a high probability of causing more harm than good to patients. It examines the history of medical literature, with a critical look at procedures that might be characterized as harmful, futile, or with excessive use of diagnostic and therapeutic methods. RESULTS: This analysis revealed evidence that such procedures have been taking place throughout many periods of history. Studies have shown that the current prevalence of inappropriate medical procedures can be as high as 29\% in the United States and $80 \%$ of cases for some individual services around the world. Lack of reliable data thwarts accurate analysis of the prevalence of overuse before the last decade. CONCLUSIONS: Instead of a recent phenomenon, overuse has permeated medical practice from its beginnings until today, regardless of technological advances, and is possibly inherent to the human species.

KEYWORDS: History. Medicine. Overuse. Physician. 
The origins of medical practices go back to the beginnings of the most ancient civilizations. There have been significant changes in the form, management, knowledge, and conduct of professional physicians throughout history. Overuse has recently been often discussed, and its many implications regarding treatments and requests for diagnostic tests. Medical overuse is defined as futile, low-value procedures characterized by excessive use of methods with a high probability of causing more harm than good to patients. 1 Mentions of overuse tend to imply it is a recent phenomenon as if irrationality was brought about by technological advances and the development of new procedures. However, it is possible that physicians have been prone to the same cognitive biases since antiquity, also performing inappropriate and excessive procedures. This raises the question of whether the contemporary issue of overuse is a modern phenomenon or inherited from a multi-millennial medical tradition.

This report begins with describing aspects and historical facts, from the origins of the medical practice to the latest advances in technologically sophisticated diagnostic resources. The account highlights the role of physicians in these diverse and divergent settings, with their duties, limitations, liabilities, and powers facing inherent decisions of their acts.

The purpose of this article is to summarize the medical literature about overuse throughout the history of medicine. It seeks to infer whether, according to the current conception, it is a contemporary issue or inherent to the medical essence, having been present since the beginnings of the medical practices. Our research started with a systematic review of literature in general databases (PUBMED, EMBASE, LILACS). However, being it a recent area of study, no reliable data was found in publications prior to a decade, thwarting an accurate assessment of overuse before that. Following, we searched for reviews in literature, especially in sources in the history of medicine, which indicated conditions that might predispose excessive, harmful, mythical, or futile medical procedures.
The Egyptian Imhotep (2667 - 2648 BCE) $)^{2}$ is the first physician in history known by name. The Ebers Papyrus is among the oldest documents of ancient Egyptian medicine, describing surgical procedures and combining knowledge of about 700 remedies and magical formulas. This papyrus, for instance, even refers to incantations to avert disease-causing demons. 3 Another important ancient document, the Edwin Smith Papyrus, contains references to observations about the practice of medicine and some treatments. ${ }^{4}$ Even though its approach is more rational, describing injuries, fractures, and luxations, it still cites religious beliefs. References available were limited, and it is plausible to infer that medicine went hand in hand with magic in its first steps, possibly sharing beliefs and dogmas. From this point of view, it is possible to reason that medicine originated from mythical and futile thinking in antiquity, conforming with the concept of overuse. This relates to how Homo sapiens' mind operates, based on a genetically encoded arsenal of beliefs, folklore, and heuristics that synthesize in mental shortcuts to facilitate decision making. ${ }^{-}$

Procedures were mainly based on mythical thinking and beliefs, faith, and intuition, predisposing to a higher number of procedures as they depended only on physicians' imagination. Practices were closer related to habits and repetition than to any form of science, yet undeveloped, as skepticism was not part of the medical thinking toolbox. Historical references to therapeutic substances such as the use of salicylates, precursors to acetylsalicylic acid 3 , that stood the test of time are rare exceptions.

Many schools are cited throughout the history of medicine. Perhaps the most widely known and celebrated is the Hippocratic. The Greek physician, Hippocrates of Kos (460 - 370 BCE), the "Father of Medicine" $\underline{6}$, laid the foundations for the emergence and development of rationality in medical practice by separating medicine from religious rituals and 
rejecting the superstition and magical practices of the primitive activities. That way, he fought against overuse in the form of futile and mythical procedures. He was the first to classify diseases as acute or chronic, endemic, or epidemic, and introduced terms such as exacerbation, relapse, resolution, crisis, paroxysm, peak, and convalescence.

Galen (129-217 CE) was one of the most renowned surgeons of the ancient world, having performed numerous surgeries, some of which were audacious, including ophthalmological and neurological interventions. ${ }^{?}$ It is attributed to him to have said that "For unless the patient admires his doctor as a god, he will not follow his treatment willingly." Such thinking raised the physician to the level of a demigod and imposed a passive stance on the patient. While performing unlimited divine procedures, the physician consequently promoted overuse. Firstly, by dispensing with evidence of good from his therapies, as divinity is always right, and secondly, by discouraging questioning and reflection on the chosen course of action.

Furthermore, there was a predisposition to solve problems actively, to the detriment of watchful waiting. One of the most used therapies at that time was the theriaca ${ }^{8}$, a multipurpose concoction, a panacea, for which Galen was an enthusiast. Theriaca was used frequently to treat infectious diseases, febrile syndromes, vision disturbances, dizziness, vertigo, and other ailments. 9 Typical of overuse, its use was widespread, excessive, exaggerated, and based solely on observation.

In this period, however, a focus on the history of the disease, detailed descriptions of symptoms, combination with findings of clinical examinations, and increasing numbers of signs made the diagnosis of diseases progressively enlightened. All the while, the more experienced served as advisors and preceptors for the initiates. The foundation of medical diagnosis consisted of anamnesis, detailed clinical examination, and following the evolution of illnesses.
The physician-patient relationship was based on patient knowledge and mutual trust, even though still asymmetrical in power.

Physicians and patients seemed at times to be waiting for miracles. The word miracle derived from Late Latin mīrāculum, meaning to wonder at extraordinary events, had no plausible explanation considering the knowledge and methods of the day.

In their absence, physicians practiced their art, using drugs with no proof of effectiveness, treating patients based on religious beliefs, fantasy, observation, and repetition of medical procedures.

\section{Medicine in the Middle Ages}

In this period, physicians had little to almost no understanding of human anatomy. For a long time, medieval medicine was practiced mainly by monks, the only ones who had access to the best medical literature of the time. It is difficult to determine how much overuse there was in the Middle Ages, given the scarce literary accounts with reasonable statistics, if any. The following are accounts of common and frequent events of the period in which the lack of scientific basis for the exercise of medical practice is patent. The inconsistency of efficacy and the excessive use of harmful methods show how banal overuse possibly was.

Given the extremely unsatisfactory conditions, surgery was only performed in cases of grave risk. Findings of trepanned skulls from this period show that some patients survived this sort of intervention. Some anesthetics used to alleviate pain or induce sleep were potentially fatal. Despite improvements to some aspects of treatments, belief in unscientific rationale was still widespread. Medieval physicians believed many diseases were caused by excessive bodily fluids, the humors, to which the supposed cure consisted of aggressive bloodletting. There were two techniques for that, leeching and phlebotomy. 10 
Bloodletting was one of the most frequent therapies throughout this period and was used indiscriminately for several pathologies, such as fever, pneumonia, urinary tract infection, and migraines. Cataract surgery was regularly performed.11 Another odd treatment was renal lithiasis, in which physicians would identify stone-like masses by touch. The procedure consisted of introducing a perforating instrument repeatedly until the stone was removed.12

Arab scholars were among the most prolific authors in this period. . After $750 \mathrm{CE}$, the Muslim world assumed an important role in science, and Islamic physicians took part in important researches. Noteworthy Islamic pioneer physicians include Avicenna ${ }^{13}$, who, together with Imhotep ${ }^{2}$ and Hippocrates ${ }^{6}$, form the triumvirate of fathers of medicine. Avicenna wrote The Canon of Medicine, regarded as one of the most famous books in medical history. ${ }^{-}$Cauterization, treatments for trachoma and cataract, use of herbs to prevent infections, and the development of numerous hospitals are substantial contributions of Muslim medicine, which conferred more rationality and attempted to introduce scientific aspects to the medical practices. Nevertheless, this apparently did not amount to a significant reduction in medical overuse in relation to an excess of futile procedures in this period.

Physicians did not have other resources at their disposal than clinical history and propaedeutic. There was therapeutic evolution with some treatments, even though the results were very bad. At this stage, the religious fantasy begins, slowly but surely, to be superseded by procedures based on some logical, nonempirical reasoning, albeit devoid of evidence of biological plausibility or proven benefit, e.g., bloodletting, and excessively used as a panacea, reinforcing the overuse expressively. Physicians and patients seemed to hope for miracles only reached through technological and scientific advances.

\section{Renaissance medicine}

Throughout the Renaissance, from the 14th to the 17th century, knowledge increased extraordinarily via the scientific method, consisting of experiments, gathering of data, and drawing conclusions.
The foundations of scientific medicine could be considered laid. Some key findings of this era would forever change the practice and its results, causing a profound impact on the relations between physicians and patients. That raised the former to the level of scientists, akin to demigods, and reinforced overuse. The light of hope and the brightness of some people made major medical breakthroughs possible.

In 1543, Andreas Vesalius (1514 - 1564) published detailed anatomical illustrations. ${ }^{14}$ Later anatomists in Padua included Gabriele Falloppio (1523 -1562), who described female reproductive organs, and Hieronymus Fabricius (1537 - 1619), who identified heart valves. Surgery was performed almost exclusively by barbers that would oddly use the same tools for both trades. Such interventions were quite primitive and extremely painful. Cauterization still was the main form of stopping hemorrhage.

Many of Galen's misconceptions were finally dispelled. William Harvey (1578 - 1657) described the systemic circulation of blood precisely, confirming previous findings and adding information about how the heart functioned to pump blood around the body. ${ }^{15}$ Richard Lower $(1631$ - 1691) and Robert Hooke (1635 - 1703) revealed that blood incorporates some chemical element that changes its color to bright red during its passage through the lungs. $\frac{16}{16}$ Antoine Lavoisier (1743 - 1794) discovered oxygen and made it possible to understand the physiology of respiration fully. Hooke and, above all, Leeuwenhoek (1632-1723) used the then-new device called microscope to uncover a whole field of microscopic particles. For the first time in history, there was space for and presence of diagnostic instruments between physicians and patients. This would start to configure armed propaedeutic.

Thomas Sydenham (1624 - 1689), an English physician, defended the use of cinchona bark, which contains quinine, to treat malaria. James Lind (17161794) proved that citrus fruits, which contain vitamin C, cured scurvy, a serious disease that afflicted ships' crews in long-distance travels. $\frac{17}{}$ William Withering (1741 - 1799) observed the efficacy of digitalis, from foxgloves (Digitalis spp.), in the treatment of some heart pathologies. $\frac{18}{}$ Edward Jenner (1749-1823) developed a vaccine against smallpox. Vaccination was so effective that the once epidemic disease is now eradicated worldwide. 
However, with such important and remarkable breakthroughs, few of these and other advancements in scientific knowledge directly impacted everyday clinical practice. Many procedures adopted in practice were still based on fantasy and futility. Cupping, bloodletting, and purges were still the mainstream treatments. Syphilis and other sexually transmitted diseases were still treated with high doses, sometimes fatal, of mercury, as Paracelsus had prescribed. Theriaca8 remained popular and routinely and excessively used, perpetuating medical overuse by the excess of unnecessary and mythical procedures. There still was a huge gap between academic medicine and habitual clinical practice. Many patients and even physicians were unwilling to adopt new practices. Nonetheless, some extraordinary new events that could not be explained by the natural laws known in previous centuries, and so regarded as miracles, were now slowly being unveiled and finally consistently applied.

\section{The exercise of Modern and Contemporary Medicine - study of overuse}

The whole society has been modernized, following developments in many areas such as physics, mathematics, biology, and chemistry. Advances in medicine naturally followed these evolutions. With the improvement of equipment, ever more sophisticated, medical diagnosis gained accuracy, as human senses were amplified by electric signals, probes, monitoring, and diverse imagery devices. However, many unexpected findings of examinations carried out routinely or without the scrutiny of a more refined clinical reasoning would not translate into clinical relevance for the patient. In fact, very frequently, such findings lead to unfavorable consequences to patients themselves, requiring further also unnecessary examinations and procedures. Physicians seemed bedazzled with the new technologies and prone to inconsequently abuse of what was once considered "scientific miracles" and is now incorporated into medical practice.

Other issues are not as evident but reflect the practical execution of the medical work, which faces more present powers than the pharmaceutical industry and hospital conglomerates. The latter facilitates routine access to examinations, mostly unnecessary, through emergency protocols, by making use of algorithms to create a system of request for examinations. The aim, though, is to ensure proper payment to medical insurance companies. Another relevant issue is the concern about lawsuits against professionals. $\frac{19}{}$ Therefore, medical overuse greatly impacts the costs of healthcare.

Having realized that excessive examinations and procedures were not proper medical conduct and actually meant greater risk for patients and departing from ethical principles such as "primum non nocere," segments of the medical society introduced incisive measures. For instance, some medical societies have implemented Appropriate Use Criteria (AUC) policies ${ }^{20}$ to lower the number of unnecessary diagnostic examinations. Other initiatives are also important and impactful, such as Choosing Wisely21, which invites patients to the debate and reflection on the real need for examinations and procedures. All of them aim at reducing medical overuse.

\section{Conclusion and Final Considerations}

If history repeats itself, the past is a good guide for the future. The systematic study of medical overuse is relatively recent. Studies have shown that the current prevalence of inappropriate medical procedures can be as high as $29 \%$ in the United States and $80 \%$ of cases for some individual services around the world. 22 Lack of reliable data thwarts accurate analysis of the prevalence of overuse before the last decade.

The analysis of the past is done to find answers for present-day phenomena. Clues may have been erased by the time, or perhaps the existing instruments cannot find evidence or proof of occurrence. Medical thinking and decision-making processes are complex and still little comprehended. Simple strategies were frequently used to arrive at apparently adequate answers, especially in situations where the issues faced were complex. $\frac{5}{\text { Despite }}$ physicians routinely making use of principles of the scientific method, 
i.e., gathering of information through anamnesis, sequential physical examination, and formulation of diagnostic hypothesis, this does not necessarily result in rational procedures that represent economy in thought or actions grounded on higher probability of benefit to the patient. The attention to and reflection about present-day events may provide grounds and support the idea that the modus operandi of human cognition, as well as its actions, have not changed for thousands of years. This literature review concludes that medical overuse is not a recent phenomenon and is possibly inherent to the human species. Regardless of technical evolutions, it has remained present since the beginnings of medical activity. Hence, some subtle changes in characteristics of overuse throughout time were identified, with the prevalence of some aspects during certain periods: religious and mythical thinking in antiquity; inappropriate and sometimes harmful procedures and quasi-logical, nonempirical, reasoning in the Middle Ages; futility and excess of procedures in the Renaissance; and excess of procedures driven by varied forces, including technological appeal, in Modern and Contemporary Ages. No initiatives to reduce inappropriate procedures were observed before the present period. They intensified after recent studies about medical overuse. Some initiatives stand out, such as Choosing Wisely ${ }^{21}$, the implementation of Appropriate Use Criteria (AUC) policies by some medical societies ${ }^{20}$, and studies with educational interventions for the reduction of inappropriate examinations. ${ }^{23}$ Figure 1 shows some examples of medical therapies with no evidence of benefit used throughout history.

Figure 1. Examples of therapies with no evidence of benefit throughout history

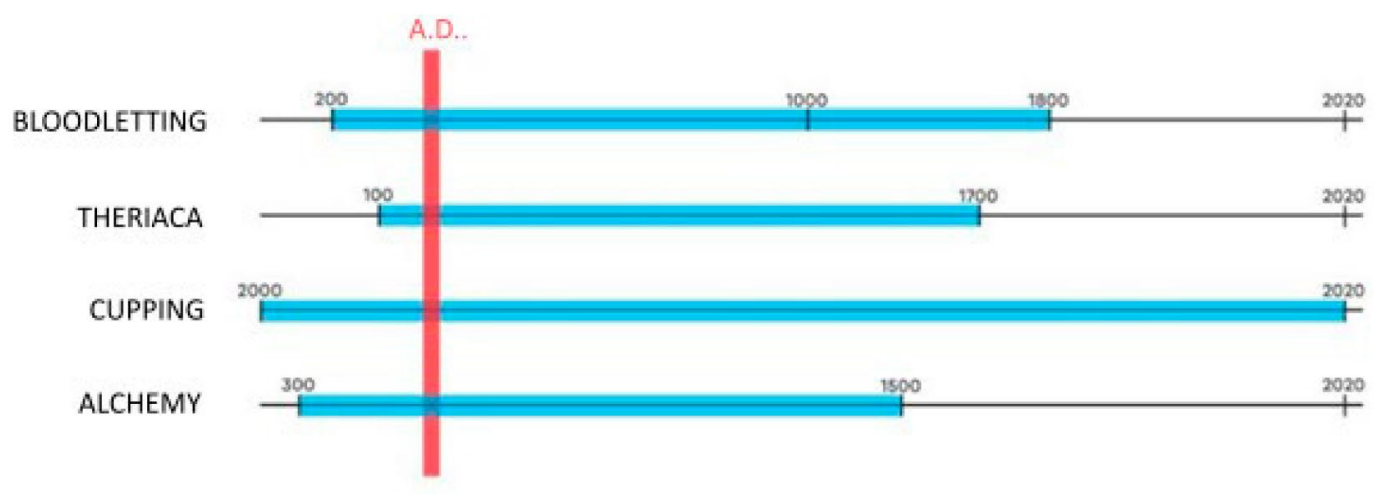

It is a difficult task to identify habits deeply rooted in professional routines. However, a reasonable proposition is using training and continuing education, emphasizing feedback and corrections to practices. Some predictions point to the taking over of some medical functions by machines and software-driven by artificial intelligence, given that they reach better, more accurate diagnoses than humans. $\frac{24,25}{}$ Notwithstanding these ideas, it is beyond dispute that some niches will remain open to healthcare workers, such as patient carers, diagnosticians of pathologies, or infirmities based on the detailed clinical history and the much relevant art of searching for propaedeutic clinical signs for a better diagnostic result.

Such movement of wider access to medical technology should be supported by the attention of experienced professionals, who in turn must acknowledge that technology and the services provided by the software, algorithms, artificial intelligence, predictive models, and calculators can be used as instruments to help, for better and more refined activities that result in positive improvement for the professional practice.

With cartesian care, and in addition to vigilance and maintenance of medical ethics, as guardians of its best practice, it will also rest upon physicians a philosophical return to the designs of the Hippocratic origins, as eternal carers of the sick and venerable keepers of the good medical science as the main legacy. These aspects, together with reasoning and wisdom, to excel in medical conduct and practice, have the potential to at last perform the miracles of the new era, those of giving health care the most appropriate, precise, elegant, economic, and distinctive use of the knowledge and methods available in medicine. 


\section{Authors' contribution}

Lopes JRP, Souza Filho J, Gomes CDC and Correia LCM contributed to the manuscript.

\section{Competing interests}

No financial, legal, or political conflicts involving third parties (government, corporations, and private foundations, etc.) have been declared for any aspect of the submitted work (including, but not limited to grants and funding, advisory board participation, study design, preparation of the manuscript, statistical analysis, etc.).

\section{References}

1. Chassin MR, Galvin RW. The urgent need to improve health care quality. Institute of Medicine National Roundtable on Health Care Quality. JAMA. 1998;280(11):1000-5. https://doi.org/10.1001/ jama.280.11.1000

2. Mikic Z. Imhotep--builder, physician, god. Med Pregl. 2008;61(910):533-8. Cited: PMID: 19203075.

3. Ali FR, Finlayson AE. Pharaonic trichology: the Ebers Papyrus. JAMA Dermatol. 2013;149(8):920. https://doi.org/10.1001/ jamadermatol.2013.4240

4. Vargas A, Lopez M, Lillo C, Vargas MJ. The Edwin Smith papyrus in the history of medicine. Rev Med Chil. 2012;140(10):1357-62. https://doi.org/10.4067/s0034-98872012001000020

5. Silva GAR. The decision making process in clinical practide: medicine as a state of the art practice. Rev. Soc. Bras. Clín. Méd [Internet]. 2013;11(1):75-9. Available from: http://bases.bireme.br/ cgi-bin/wxislind.exe/iah/online/?lsisScript=iah/iah.xis\&base=LILACS\&lang=p\&nextAction=Ink\&exprSearch=668517\&indexSearch $=$ ID

6. Yapijakis C. Hippocrates of Kos, the father of clinical medicine, and Asclepiades of Bithynia, the father of molecular medicine. Review. In Vivo. 2009;23(4):507-14. Cited: PMID: 19567383.

7. Cordeiro M. Príncipes da Medicina. Saída de Emergência;1995.

8. Havik PJ. Hybridising Medicine: Illness, Healing and the Dynamics of Reciprocal Exchange on the Upper Guinea Coast (West Africa). Med Hist. 2016;60(2):181-205. https://doi. org/10.1017/mdh.2016.3

9. Watson G. Theriac and Mithridaticum - A Study in Therapeutics. London: The Wellcome Hsistorical Medical Library; 1966.

10. Ialongo C, Bernardini S. Phlebotomy, a bridge between laboratory and patient. Biochem Med (Zagreb). 2016;26(1):17-33. https://dx.doi.org/10.11613\%2FBM.2016.002
11. Davis G. The Evolution of Cataract Surgery. Mo Med. 2016;113(1):58-62. PMID: 27039493.

12. Tefekli A, Cezayirli F. The history of urinary stones: in parallel with civilization. ScientificWorldJournal. 2013;2013:423964. https://doi.org/10.1155/2013/423964

13. Hajar RMD. The air of history (part v) ibn sina (avicenna): the great physician and philosopher. Heart Views. 2013;14(4):196-201. https://dx.doi.org/10.4103\%2F1995-705X.126893

14. Benini A, Bonar SK. Andreas Vesalius 1514-1564. Spine (Phila Pa 1976). 1996;21(11):1388-93. https://doi.org/10.1097/00007632199606010-00024

15. McMullen ET. Anatomy of a physiological discovery: William Harvey and the circulation of the blood. J R Soc Med. 1995;88(9):491-8. Cited: PMID: 7562843.

16. Donovan AJ. Richard Lower, M.D., physician and surgeon (1631-1691). World J Surg. 2004;28(9):938-45. https://doi. org/10.1007/s00268-004-7553-7

17. Bhatt A. Evolution of clinical research: a history before and beyond James Lind. Perspect Clin Res 2010;1(1):6-10. Cited: PMID: 21829774.

18. Wilkins MR, Kendall MJ, Wade OL. William Withering and digitalis, 1785 to 1985. Br Med J (Clin Res Ed). 1985;290(6461):7-8. https://dx.doi.org/10.1136\%2Fbmj.290.6461.7

19. Huang $X$, Rosenthal MB. Overuse of Cardiovascular Services: Evidence, Causes, and Opportunities for Reform. Circulation. 2015;132(3):205-14. https://doi.org/10.1161/ circulationaha.114.012668

20. Douglas PS, Garcia MJ, Haines DE, Lai WW, Manning WJ, Patel AR, et al. ACCF/ASE/AHA/ASNC/HFSA/HRS/SCAI/SCCM/ SCCT/SCMR 2011 appropriate use criteria for echocardiography: a report of the American College of Cardiology Foundation Appropriate Use Criteria Task Force, American Society of Echocardiography, American Heart Association, American Society of Nuclear Cardiology, Heart Failure Society of America, Heart Rhythm Society, Society for Cardiovascular Angiography and Interventions, Society of Critical Care Medicine, Society of Cardiovascular Computed Tomography, Society for Cardiovascular Magnetic Resonance American College of Chest Physicians. J Am Coll Cardiol 2011;57(3):1126-66. https://doi.org/10.1016/j.echo.2010.12.008

21. Born KB, Levinson W. Choosing Wisely campaigns globally: A shared approach to tackling the problem of overuse in healthcare. J Gen Fam Med. 2019;20(1):9-12. https://dx.doi. org/10.1002\%2Fjgf2.225

22. Brownlee S, Chalkidou K, Doust J, Elshaug AG, Glasziou P, Heath I, et al. Evidence for overuse of medical services around the world. Lancet. 2017;390(10090):156-68. https://doi.org/10.1016/ $\underline{\text { S0140-6736(16)32585-5 }}$ 
23. Bhatia RS, Ivers NM, Yin XC, Myers D, Nesbitt GC, Edwards J, et al. Improving the Appropriate Use of Transthoracic Echocardiography: The Echo WISELY Trial. J Am Coll Cardiol. 2017;70(9):1135-44. https://doi.org/10.1016/j.jacc.2017.06.065

24. Lamy JB, Sekar B, Guezennec G, Bouaud J, Seroussi B. Explainable artificial intelligence for breast cancer: A visual case-based reasoning approach. Artif Intell Med. 2019;94:42-53. https://doi.org/10.1016/j.artmed.2019.01.001
25. Panch T, Szolovits P, Atun R. Artificial intelligence, machine learning and health systems. J Glob Health. 2018;8(2):020303. https://dx.doi.org/10.7189\%2Fjogh.08.020303 